\title{
Accurate measurements and establishment of a model of the mechanical properties of dried corn kernels
}

\author{
Jiachang Feng, Zidan Wu, Debo Qi, Yi Jin, and Wenfu Wu* \\ Department of Biological and Agricultural Engineering, Jilin University, Changchun, China
}

Received June 23, 2018; accepted December 11, 2018

\begin{abstract}
Mechanical drying significantly affects the mechanical properties of corn kernels. Improper drying may result in material losses and in a decline in quality due to pressure, collisions, and other factors during subsequent storage and transport operations. A literature survey revealed that at time of writing the characteristics of dried corn kernels have not been systematically and fully studied. In this paper, an orthogonal rotation combination test scheme was designed. Using a multiparameter controllable thin layer drying test bench, corn was dried under different conditions (temperature $30-60^{\circ} \mathrm{C}$, relative humidity $30-60 \%$, air velocity 0.46-0.94 $\mathrm{m} \mathrm{s}^{-1}$, initial moisture content of corn of $20-30 \%$ w.b., tempering ratio $0-3)$. Then, a texture analyser was used to measure the mechanical properties (rupture force, rupture energy, modulus of elasticity and brittleness) of the dried corn kernels. Relationship models were established for the rupture force, rupture energy, modulus of elasticity and brittleness and drying conditions of corn kernels. An increase in the drying temperature from 30 to $60^{\circ} \mathrm{C}$ increased the rupture energy, elastic modulus, and brittleness of the corn kernels by $19.11,11.76$, and $4.02 \%$, respectively; an increase in the drying relative humidity from 30 to $60 \%$ increased the rupture force, energy, modulus of elasticity and brittleness by $15.07,13.74,20.73$, and $3.31 \%$, respectively.
\end{abstract}

Keyw ord s: thin layer drying, corn kernel, mechanical property, model

\section{INTRODUCTION}

As an important food and commercial feed crop, corn is widely grown in many countries, including China, and it is an important staple food for humans and animals. At harvest time, the moisture content of corn ranges from 25 to $35 \%$ (Marques da Silva and Silva, 2006), which is not a suitable range for storage. Corn must be dried with heated air until it reaches an acceptable moisture content for storage and processing.

*Corresponding author e-mail: wwfzlb@126.com
Thin layer drying in a convective atmosphere is a process by which corn is fully exposed to the heating medium under different drying conditions; this process is the basis for the study of deep-bed drying (Doymaz and Pala, 2003). The study concerning the mechanical properties of corn kernels aims to determine the mechanical properties, such as rupture force, failure energy, deformation under load and brittleness of corn, and to provide data regarding the compression and collision of corn during transportation and storage (Cheng et al., 2016).

Studies concerning the mechanical properties of food grains began in the 1960s. Prasad and Gupta (1973) performed a quasistatic compression test to determine the resilience of rice kernels. The effect of moisture content on the mechanical properties of faba bean grains has been investigated (Altuntaş and Yildız, 2007). The results showed that the specific deformation and rupture energy of faba bean grains increased in magnitude with an increase in moisture content, but rupture force decreased; the maximum rupture force was on the $\mathrm{Z}$ axis, which is the shortest axis. According to (Zareiforoush et al., 2010), the compression azimuth and loading and unloading rates substantially impact paddy grain compression characteristics. Kiani et al. (2011) determined Poisson's ratio and Young's modulus of elasticity for red bean grains with different moisture contents $(5,7.5,10,12.5$ and $15 \%$ w.b.), and the results may be used to design harvesting machines or other mechanical devices.

During the drying process, the moisture gradient increases, the internal structure shrinks, and the internal stress of the cereal grains increase due to the reduction in moisture content. Different drying methods and drying conditions exert different effects on changes to the internal

(C) 2019 Institute of Agrophysics, Polish Academy of Sciences 
stress of cereals. Hence, it is necessary to study the changes to the mechanical properties of cereal grains under different drying conditions (Pawlak, 2003).

Woźniak, Niewczas and Kudra (1999) showed that the correlations between the drying conditions and mechanical properties of wheat grain were significant, however, the effect of the initial moisture content on the mechanical properties was not significant. Davidson et al. (2000) conducted an experiment with a thin layer dryer to investigate the relationship between drying conditions and the physical qualities of corn in terms of kernel stress cracks and breakage susceptibility. The drying conditions were established using four levels of drying air temperature $(40,60,80$, and $100^{\circ} \mathrm{C}$ ) and two levels of drying medium humidity (air saturation temperatures of 5 and $25^{\circ} \mathrm{C}$ ). Both stress cracking and breakage susceptibility increased with drying temperature, and the higher level of drying air humidity resulted in a much longer drying time at the lowest air temperature $\left(40^{\circ} \mathrm{C}\right)$. Kalantari and Eshtavad (2013) investigated the effect of different tempering periods on rice grain breakage in a thin layer dryer. They established four drying temperatures $\left(40,50,60\right.$, and $\left.70^{\circ} \mathrm{C}\right)$ and four levels of tempering ambient pressure $(0.4,0.6,0.8$, and $1.0 \mathrm{~atm})$ and found that after drying at 50 and $60^{\circ} \mathrm{C}$ at $0.8 \mathrm{~atm}$, the minimum crack rates occurred within 1 and $2 \mathrm{~h}$ of tempering time, respectively. However, the authors did not consider the effect of the humidity of the drying medium on the results. Talab et al. (2012) measured the glass transition temperature of rice with different moisture contents and compared the hardness of the rice grains exposed to different drying temperatures. Rice exposed to a drying temperature ranging from $55-60^{\circ} \mathrm{C}$ was harder than rice dried under other conditions. The authors explained that this phenomenon was caused by the use of a drying temperature that was higher than the glass transition temperature of rice, which caused the grain to change to a glassy state and increased its hardness. Aquerreta et al. (2007) compared the effects of tempering temperatures after high-temperature drying $\left(60^{\circ} \mathrm{C}\right)$ on the rice dehydration rate and head rice yield. The tempering temperatures used in the experiment were the ambient temperature $\left(20^{\circ} \mathrm{C}\right), 40$ and $60^{\circ} \mathrm{C}$. After hightemperature $\left(60^{\circ} \mathrm{C}\right)$ tempering, the number of cracks in the rice decreased, and the drying time was reduced by $38 \%$ with the same dehydration rate, which is very important for the processing of dried rice. Nevertheless, the authors did not consider the tempering time, and the experimental results were not sufficiently comprehensive. Lewicki and Jakubczyk (2004) studied the changes in the mechanical properties of apple slices exposed to different drying temperatures and moisture content conditions. Changes in the mechanical stress resistance of apples after drying at 50,60, and $70^{\circ} \mathrm{C}$ were not significant, but compared with apples dried at $80^{\circ} \mathrm{C}$, the loading-unloading curve of the apple slices changed significantly. Minaei (2014) determined the mechanical properties of corn kernels dried at different dry- ing temperatures. During the test, the drying temperature was set to $40,50,60$, or $70^{\circ} \mathrm{C}$, and the air flow rate was stable at $1.8 \mathrm{~kg} \mathrm{~min}^{-1}$. According to his report, when the drying temperature increased from 40 to $70^{\circ} \mathrm{C}$, the stress, toughness, and elastic modulus of the corn kernels decreased by 26,36 , and $38 \%$, respectively, and the deformation value increased by $12.29 \%$. However, this study lacked an examination of the influences of the initial moisture content of the sample and tempering time on the test results, also, the relative humidity of the drying medium was not controlled.

A review of the literature revealed few studies designed to determine the mechanical properties of cereals after drying. Papers related to the characteristics of dry grain traits are not sufficiently comprehensive, as some parameters could not be controlled with sufficient accuracy, which renders the relevant data and models less applicable and increases the gap between their qualitative conclusions. In the present study, a multiparameter accurately controllable thin layer drying test was conducted based on a thorough consideration of the drying process conditions (medium temperature, relative humidity, initial moisture content, air velocity, and tempering ratio). The rupture force, rupture energy, brittleness, and elastic modulus of the dried corn kernels were accurately determined, and models investigating the relationships between the mechanical properties and drying conditions were constructed, providing a databased foundation for the storage, processing and quality determination of corn.

\section{MATERIALS AND METHODS}

Corn kernel samples were stored under vacuum at $4{ }^{\circ} \mathrm{C}$ for 2 weeks before the experiment. The variety of corn was Xianyu 335 with an initial moisture content of $32 \%$ w.b., which was produced in autumn 2017 in Yongji County, Jilin Province, China. The corn samples were removed from their vacuum packaging $2 \mathrm{~h}$ before the experiment began. Then, 50 subsamples of the corn kernels were randomly selected, and their lengths, widths, and heights were determined using digital callipers. The average size of the corn kernels was a length of $12.137 \pm 0.1643 \mathrm{~mm}$, a width of $9.226 \pm 0.2232 \mathrm{~mm}$, and a height of $4.135 \pm 0.1826 \mathrm{~mm}$.

The experimental design was established using the five-factor quadratic rotation combination method. The drying conditions were controlled and included the drying medium temperature, relative humidity $(\mathrm{RH})$, initial moisture content of corn (IMC), velocity, and tempering ratio. A five-factor and five-level orthogonal experimental table is shown in Table 1.

The range of drying temperatures was determined based on the national standard method (GB/T, 21017-2007). According to the national standard, the allowable heating temperature of corn during drying is less than $60^{\circ} \mathrm{C}$. Since the grain temperature is similar to the hot air temperature in thin layer drying, the drying medium temperature vari- 
ations in this paper ranged between 30 and $60^{\circ} \mathrm{C}$. The $\mathrm{RH}$ of the drying medium was determined by measuring the $\mathrm{RH}$ at the air outlets from multiple continuous corn dryers in the previous period. The RH of the tidal outlet ranged from 20 to $60 \%$; therefore, the range of the RH of the drying medium in this paper was $30-60 \%$. Similarly, the drying air velocity was determined by measuring the wind speed in the hot air ducts of multiple continuous corn dryers. According to the moisture content of the sampled corn, the IMC of the tested corn was set to 20 to $30 \%$ w.b. Currently, the tempering ratio of mainstream continuous corn dryers does not exceed 3 ; therefore, the tempering ratio ranged from $0-3$ in the present study.

Table 1. Five-factor and five-level orthogonal experimental table

\begin{tabular}{lccccc}
\hline & \multicolumn{5}{c}{ Factor } \\
\cline { 2 - 6 } Level & $\begin{array}{c}A \\
\text { Drying } \\
\text { temperature } \\
{ }^{\circ} \mathrm{C}\end{array}$ & $\begin{array}{c}B \\
\text { Relative } \\
\text { humidity } \\
\%\end{array}$ & $\begin{array}{c}C \\
\text { Initial } \\
\text { moisture } \\
\text { content } \\
\%\end{array}$ & $\begin{array}{c}D \\
\text { Velocity } \\
\mathrm{m} \mathrm{s}^{-1}\end{array}$ & $\begin{array}{c}E \\
\text { Tempering } \\
\text { ratio }\end{array}$ \\
\hline 2.378 & 60 & 60 & 32 & 0.94 & 3 \\
1 & 51.3 & 51.3 & 28.52 & 0.8 & 2.13 \\
0 & 45 & 45 & 26 & 0.7 & 1.5 \\
-1 & 38.7 & 38.7 & 23.48 & 0.6 & 0.87 \\
-2.378 & 30 & 30 & 20 & 0.46 & 0 \\
\hline
\end{tabular}

The multiparameter controllable dryer for this experiment could precisely control the drying medium temperature, RH and velocity. The dryer's adjustment range of temperature was room temperature to $100^{\circ} \mathrm{C}$ (accuracy $\pm 1^{\circ} \mathrm{C}$ ), the RH was $25-70 \%$ (accuracy $\pm 3 \%$ ), and the velocity was $0.4-1 \mathrm{~m} \mathrm{~s}^{-1}$ (accuracy $\pm 0.01 \mathrm{~m} \mathrm{~s}^{-1}$ ). The basic working process was to heat the air by means of a heating wire. The axial fan located at the upper part of the machine caused the hot air to flow axially, and the air was divided by the conical surface. Eventually the air returned to the wire for heating. In the process, if the humidity sensor detected that the RH of the air was $2 \%$ less than the set value or lower, the program would activate the air humidifier. If the detected humidity was $2 \%$ higher than the set value or higher, the program would activate the exhaust fan. In this way, the stability of the RH of the drying medium was assured. The internal air circulation could recycle the tail gas and maintain constant air humidity in the device.

Before the beginning of the experiment, a certain amount of corn grain was taken out of the refrigerator and restored to room temperature. The moisture content of the sample was determined by a moisture meter, and the moisture content of the corn was adjusted to the required IMC by natural air-drying. The value of each drying parameter was set on a digital controller. After starting the test, the value of the main parameter reached a set value, which was controlled and stabilized on a display. Using the material tray, $1000 \mathrm{~g}$ of corn grain was loaded and placed in the warehouse. The thickness of the corn heap in the box was $50 \mathrm{~mm}$. The warehouse door was closed to allow drying to continue. After
15 min of drying, the material bin door was opened, and the corn sample was removed, weighed and placed in a tempering box for tempering. The tempering temperature was the same as the drying temperature, and drying continued after tempering. The PC program included a weighing method to measure the grain water equation and obtain real-time corn moisture content data. The moisture content of every test group was determined using the standard oven method (ASABE, 2012). When the moisture content was reduced to approximately $14.5 \%$ w.b., the door was opened every $15 \mathrm{~min}$, and a $70 \mathrm{~g}$ corn sample was removed. Three samples were removed, and when the selected oven-measured moisture was approximately $14 \%$ w.b., the sample was inserted in a sealed bag and placed in a desiccator. Tempering was no longer performed during sampling. Then, 30 corn kernels were removed from each group to determine their size and the average length, width, and height. A total of 59 sets of experiments were conducted.

Uniaxial compression tests were conducted using a CT3 texture analyser (Brookfield) with a load cell of $50 \mathrm{~kg}$ connected to a PC with specialized software. The cylindrical probe used in the present study was TA10, and the loading rate used for all tests was $0.02 \mathrm{~mm} \mathrm{~s}^{-1}$, the compression distance was $0.6 \mathrm{~mm}$, and the compression trigger load was $10 \mathrm{~g}$. Every test was performed on just one kernel, and the compression force was measured in the direction along the shortest axis of the corn kernel since this axis is the main direction of force during the cracking process. The rupture force $(F r)$, rupture energy $(E r)$ and brittleness were directly obtained using software on a PC connected to a texture analyser. The $F r$ and deformation values represented the force and deformation at the rupture point, respectively, and the $E r$ was the area under the curve for the rupture point. The brittleness value was the time taken to reach the rupture point, and a shorter time represented a more brittle corn kernel (Liu, 2011).

The modulus of elasticity $(\mathrm{Em})$ of the corn kernels was estimated using the following standard equations (ASAE, 2003):

$$
\begin{gathered}
R_{1}=\frac{H}{2}, \\
R_{1}^{\prime}=\frac{H^{2}+\frac{L^{2}}{4}}{2 H}, \\
E m=\frac{0.338 K^{1.5} F\left(1-\mu^{2}\right)}{d^{1.5}}\left[\left(\frac{1}{R_{1}}+\frac{1}{R_{1}^{\prime}}\right)^{1 / 3}+\left(\frac{1}{R_{2}}+\frac{1}{R_{2}^{\prime}}\right)^{1 / 3}\right]^{3 / 2},
\end{gathered}
$$

where: $L-$ the average width of the corn kernels (m); $H$ - the average height of the corn kernels (m); $R_{1}$ - the minimum radius of the corn kernels $(\mathrm{m}) ; R^{\prime}{ }_{1}$ - the maximum radius of the corn kernels (m); Em - the modulus of elasticity $(\mathrm{Pa}) ; K-$ a constant; $F-$ load $(\mathrm{N}) ; \mu$ - Poisson's ratio (assumed to be 0.32 for corn, regardless of its moisture content and variety) (AbdEl Maksoud, 2009); $d$ - sample deformation under loading $(\mathrm{m}) ; R_{2}$ - the minimum radius of the curvature of the upper plate (m); and $R_{2}^{\prime}$ - the maximum radius of the curvature of the upper plate $(\mathrm{m})$. 
Data were statistically analysed using Design-Expert 8.0 software to investigate the effect of drying conditions on the mechanical properties of dried corn and establish models for the relationships between the drying parameters and mechanical properties. Duncan's multiple range tests were used to establish the differences between the mean values at a confidence level of $0.05(\mathrm{p}<0.05)$.

\section{RESULTS AND DISCUSSION}

According to Table 2, the effect of the drying medium temperature and velocity on $\mathrm{Fr}$ was not significant, whereas the $\mathrm{RH}, \mathrm{IMC}$ and tempering ratio significantly influenced $F r$. The drying medium RH had the most pronounced effect (31.25) on the $F$ value. Similarly, the IMC had a greater influence on $\mathrm{Fr}$ than the tempering ratio. This finding contradicted a previous report, which stated that IMC had no effect on the mechanical properties of corn after drying (Woźniak, Niewczas and Kudra, 1999). The quadratic model of $\mathrm{Fr}$ and its drying parameters are shown in Table 3. A, $\mathrm{B}, \mathrm{C}, \mathrm{D}$, and $\mathrm{E}$ in the models represent the drying temperature, the RH of the drying medium, the IMC, the velocity, and the tempering ratio, respectively.

Table 2. ANOVA of the influence of various drying parameters on the $\mathrm{Fr}$ of corn kernels

\begin{tabular}{lrrrrr}
\hline Source & $\begin{array}{r}\text { Sum of } \\
\text { squares }\end{array}$ & DF & Mean square & $F$ value & Prob. $>F$ \\
\hline Model & 19814.71 & 14 & 1415.34 & 33.29 & $<0.0001$ \\
A & 43.17 & 1 & 43.17 & 1.02 & 0.3191 \\
B & 1328.31 & 1 & 1328.31 & 31.25 & $<0.0001$ \\
C & 1162.53 & 1 & 1162.53 & 27.35 & $<0.0001$ \\
D & 14.10 & 1 & 14.10 & 0.33 & 0.5675 \\
E & 800.38 & 1 & 800.38 & 18.83 & $<0.0001$ \\
AC & 398.11 & 1 & 398.11 & 9.36 & 0.0038 \\
BD & 975.37 & 1 & 975.37 & 22.94 & $<0.0001$ \\
BE & 1070.63 & 1 & 1070.63 & 25.18 & $<0.0001$ \\
CD & 2205.36 & 1 & 2205.36 & 51.88 & $<0.0001$ \\
$A^{2}$ & 4549.94 & 1 & 4549.94 & 107.03 & $<0.0001$ \\
$B^{2}$ & 582.36 & 1 & 582.36 & 13.70 & 0.0006 \\
C $^{2}$ & 1543.48 & 1 & 1543.48 & 36.31 & $<0.0001$ \\
D $^{2}$ & 3245.79 & 1 & 3245.79 & 76.35 & $<0.0001$ \\
E $^{2}$ & 1765.20 & 1 & 1765.20 & 41.52 & $<0.0001$ \\
Residual & 1870.53 & 44 & 42.51 & & \\
Lack of fit & 740.07 & 28 & 26.43 & 0.37 & 0.9890 \\
Pure error & 1130.46 & 16 & 70.65 & & \\
\hline
\end{tabular}

The simultaneous effects of the $\mathrm{RH}$ and velocity of the drying medium on the rupture force are shown in Fig. 1a. The greater the velocity, the more significant the effect of $\mathrm{RH}$ on the rupture force. This finding may be related to the effect of the RH of the drying medium on the distribution of moisture during drying. When the velocity was $0.6 \mathrm{~m} \mathrm{~s}^{-1}$, a significant change in $F r$ was not observed; however, when the velocity increased to $0.8 \mathrm{~m} \mathrm{~s}^{-1}$, the $\mathrm{Fr}$ increased by $14.19 \%$ as the RH increased from 30 to $60 \%$. As shown in Fig. 1b, the highest $F r$ value was obtained at the highest drying $\mathrm{RH}$ and highest tempering ratio. As the $\mathrm{RH}$

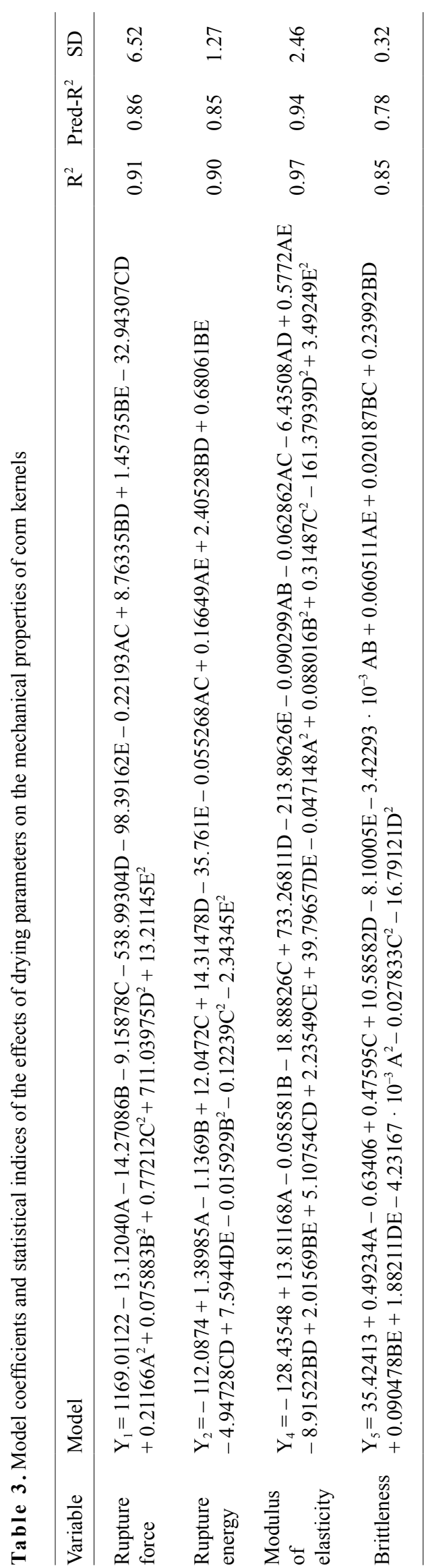


increased, the tempering ratio exerted a more significant effect on $F r$. When the RH was $30 \%$, the $F r$ changed by $9.99 \%$ as the tempering ratio changed from 0.87 to 2.13 . For the $\mathrm{RH}$ value of $60 \%$, a $19.18 \%$ variation in this index was observed.

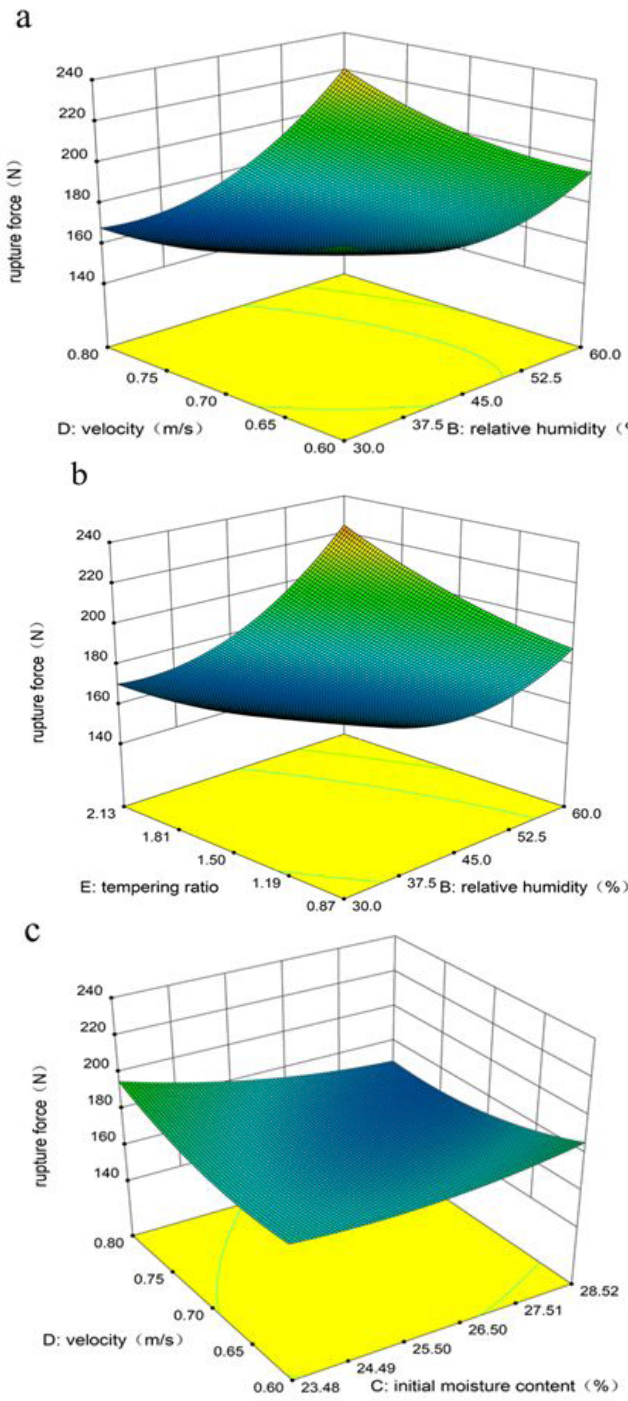

Fig. 1. Simultaneous effect of (a) drying medium RH-velocity (b) $\mathrm{RH}$-tempering ratio and (c) IMC-velocity on rupture force.

In agreement with the description presented in Fig. 1a, velocity and initial moisture content exerted significant effects on $F r$ (Fig. 1c). The highest $F r$ value was observed at the lowest IMC and highest velocity. Similar trends were observed by (Chayjan and Kaveh, 2014), which indicated that the rupture force of terebinth seed increased with increasing drying medium velocity. A higher velocity and a lower IMC results in faster drying rates ( $\mathrm{Li}$ and Moray, 1984), which creates moisture gradients between the internal and external layers of the corn kernel. This change results in internal stresses and even cracks (Pawlak, 2003) and may be the reason for the reduced $F r$ of the corn kernels. The significance of the effect of the IMC on the index gradually increased as the velocity increased. The IMCinduced change in $\mathrm{Fr}$ ranged from 23.48 to $28.52 \%$ and increased by 3.46 to $13.77 \%$ as the air velocity increased from 0.6 to $0.8 \mathrm{~m} \mathrm{~s}^{-1}$. The rupture force of barnyard millet kernel $(17.87-25.20 \mathrm{~N})$, soybean $(191.09-270.66 \mathrm{~N})$, paddy grain (88.33-167.70 $\mathrm{N}$ in horizontal orientation), and terebinth seed (44.69-135.62 N) were reported by Singh et al. (2010), Tavakoli (2009), Zareiforoush et al. (2012), and Chayjan and Kaveh (2014), respectively. And Minaei 2014) indicated that the rupture force of corn decreased from 345.405 to $271.198 \mathrm{~N}$ with an increase in drying temperature form 40 to $70^{\circ} \mathrm{C}$. The rupture force of corn kernel in the present study ranged from 158 to $223.61 \mathrm{~N}$.

$E r$ is an indicator of the toughness of a material because a higher $E r$ represents the increased difficulty of breaking the material (Zhang et al., 2005).

Table 4. ANOVA of the influence of various drying parameters on the $E r$ of corn kernels

\begin{tabular}{lrrrrr}
\hline Source & $\begin{array}{r}\text { Sum of } \\
\text { square }\end{array}$ & DF & $\begin{array}{c}\text { Mean } \\
\text { square }\end{array}$ & $F$ value & Prob. $>F$ \\
\hline Model & 664.17 & 14 & 47.44 & 29.43 & $<0.0001$ \\
A & 70.73 & 1 & 70.73 & 43.88 & $<0.0001$ \\
B & 30.94 & 1 & 30.94 & 19.19 & $<0.0001$ \\
C & 19.66 & 1 & 19.66 & 12.20 & 0.0011 \\
D & 12.23 & 1 & 12.23 & 7.59 & 0.0085 \\
E & 7.14 & 1 & 7.14 & 4.43 & 0.0411 \\
AC & 24.69 & 1 & 24.69 & 15.31 & 0.0003 \\
AE & 14.00 & 1 & 14.00 & 8.69 & 0.0051 \\
BD & 73.48 & 1 & 73.48 & 45.58 & $<0.0001$ \\
BE & 233.51 & 1 & 233.51 & 144.85 & $<0.0001$ \\
CD & 49.74 & 1 & 49.74 & 30.85 & $<0.0001$ \\
DE & 7.33 & 1 & 7.33 & 4.54 & 0.0387 \\
$B^{2}$ & 25.66 & 1 & 25.66 & 15.92 & 0.0002 \\
C $^{2}$ & 38.78 & 1 & 38.78 & 24.06 & $<0.0001$ \\
E $^{2}$ & 55.54 & 1 & 55.54 & 34.45 & $<0.0001$ \\
Residual & 70.93 & 44 & 1.61 & & \\
Lack of fit & 31.15 & 28 & 1.11 & 0.45 & 0.9698 \\
Pure error & 39.79 & 16 & 2.49 & & \\
\hline
\end{tabular}

According to Table 4, all five factors exerted significant effects on the $E r$ of the corn kernels $(\mathrm{p}<0.05)$. Considering the $F$ values, the drying medium temperature exerted the greatest effect on $\operatorname{Er}$ (43.88), followed by RH, IMC, air velocity and tempering ratio. The quadratic model of the $E r$ and drying parameters is shown in Table 3 . The response surface plot of the effects of the drying parameters on this index is presented in Fig. 2. In Fig 2a, the steeper slope of the graph of the drying temperature than of the IMC side represents the greater effect of temperature than IMC on this response, confirming the results derived from the $F$ values. As shown in Fig. 2a and b, the $E r$ gradually increased as the drying temperature increased. When the $\mathrm{RH}$ of the drying medium was $45 \%$, the air velocity was $0.7 \mathrm{~m} \mathrm{~s}^{-1}$, the tempering ratio was 1.5 , and the IMC was $23.48 \%$, when the drying temperature was increased from 30 to $60^{\circ} \mathrm{C}$ and $E r$ increased by $34.62 \%$. Similar findings were made in a recent report (Chayjan and Kaveh, 2014). The results may be attributed to the impact of changes in the internal struc- 
ture of the kernel. Higher temperatures induced a greater internal shrinkage of the corn kernels, resulting in a stronger structure with limited internal flexibility and therefore a greater $E r$. Based on the slope of the graph presented in Fig. $2 b$, a greater tempering ratio results in a more significant effect of temperature on the $E r$.

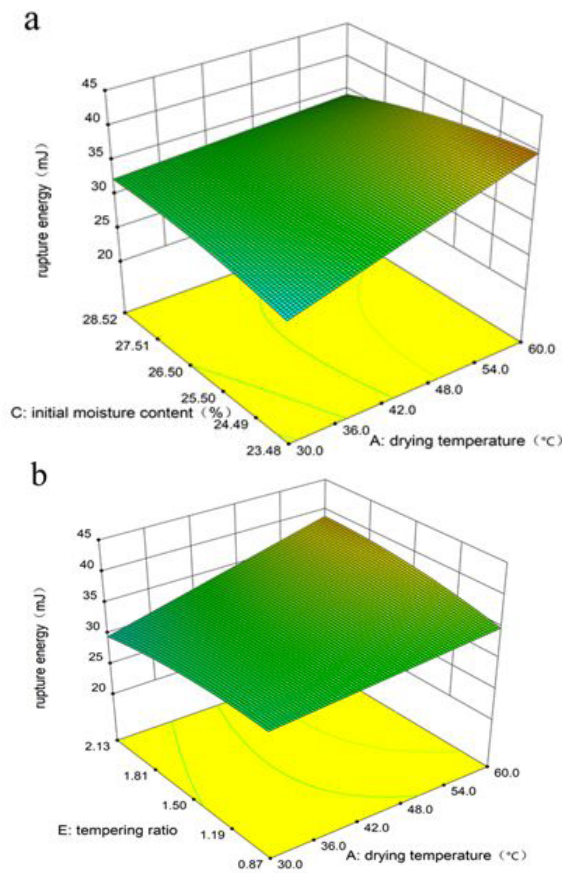

c

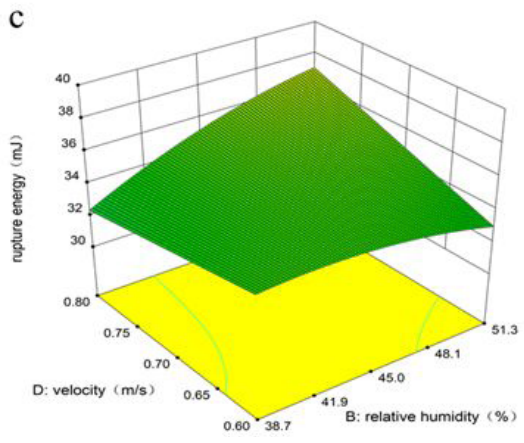

d

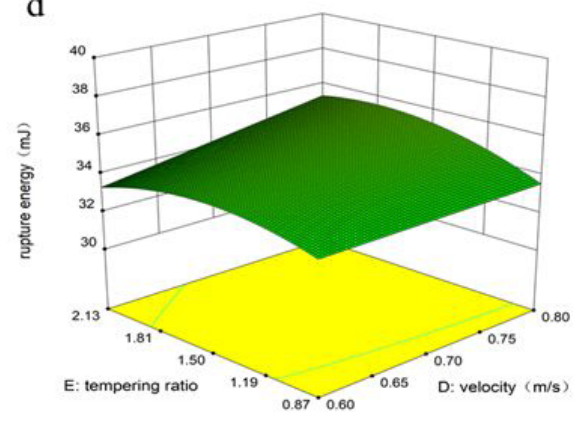

Fig. 2. Simultaneous effect of (a) drying medium temperatureIMC (b) temperature-tempering ratio (c) RH-velocity and (d) velocity-tempering ratio on rupture energy.

The RH of the drying medium and velocity had simultaneous effects on $E r$ (Fig. 2c). The highest $E r$ value was associated with drying parameters with the highest $\mathrm{RH}$ and the highest air velocity. The higher the velocity of the drying medium, the greater the significance of the effect of RH on Er. For example, when the velocity was $0.6 \mathrm{~m} \mathrm{~s}^{-1}$, the $E r$ was reduced by $1.34 \mathrm{~mJ}$ as the RH increased from 38.7 to $51.3 \%$, and when the air velocity increased to $0.8 \mathrm{~m} \mathrm{~s}^{-1}$, the index increased by $4.72 \mathrm{~mJ}$ within the same range of $\mathrm{RH}$ values.

Table 5. ANOVA of the influence of various drying parameters on the $E m$ of corn kernels

\begin{tabular}{lrrrrr}
\hline Source & $\begin{array}{r}\text { Sum of } \\
\text { squares }\end{array}$ & DF & $\begin{array}{r}\text { Mean } \\
\text { square }\end{array}$ & $F$ value & Prob. $>F$ \\
\hline Model & 7819.53 & 19 & 411.55 & 67.89 & $<0.0001$ \\
$\mathrm{~A}$ & 92.50 & 1 & 92.50 & 15.26 & 0.0004 \\
$\mathrm{~B}$ & 582.90 & 1 & 582.90 & 96.15 & $<0.0001$ \\
$\mathrm{C}$ & 690.64 & 1 & 690.64 & 113.93 & $<0.0001$ \\
$\mathrm{D}$ & 35.59 & 1 & 35.59 & 5.87 & 0.0201 \\
$\mathrm{E}$ & 9.88 & 1 & 9.88 & 1.63 & 0.2093 \\
$\mathrm{AB}$ & 411.91 & 1 & 411.91 & 67.95 & $<0.0001$ \\
$\mathrm{AC}$ & 31.94 & 1 & 31.94 & 5.27 & 0.0272 \\
$\mathrm{AD}$ & 527.07 & 1 & 527.07 & 86.94 & $<0.0001$ \\
$\mathrm{AE}$ & 168.31 & 1 & 168.31 & 27.76 & $<0.0001$ \\
$\mathrm{BD}$ & 1009.47 & 1 & 1009.47 & 166.52 & $<0.0001$ \\
$\mathrm{BE}$ & 2048.14 & 1 & 2048.14 & 337.85 & $<0.0001$ \\
$\mathrm{CD}$ & 53.01 & 1 & 53.01 & 8.74 & 0.0053 \\
$\mathrm{CE}$ & 403.07 & 1 & 403.07 & 66.49 & $<0.0001$ \\
$\mathrm{DE}$ & 201.15 & 1 & 201.15 & 33.18 & $<0.0001$ \\
$\mathrm{~A}^{2}$ & 225.78 & 1 & 225.78 & 37.24 & $<0.0001$ \\
$\mathrm{~B}^{2}$ & 783.46 & 1 & 783.46 & 129.24 & $<0.0001$ \\
$\mathrm{C}^{2}$ & 256.68 & 1 & 256.68 & 42.34 & $<0.0001$ \\
$\mathrm{D}^{2}$ & 167.20 & 1 & 167.20 & 27.58 & $<0.0001$ \\
$\mathrm{E}^{2}$ & 123.36 & 1 & 123.36 & 20.35 & $<0.0001$ \\
Residual & 236.43 & 39 & 6.06 & & \\
Lack of fit & 91.84 & 23 & 3.99 & 0.44 & 0.9639 \\
Pure error & 144.58 & 16 & 9.04 & & \\
\hline
\end{tabular}

The simultaneous effects of air velocity and the tempering ratio on the $E r$ are depicted in Fig. 2d. The lowest $E r$ value was observed at the lowest air velocity and the lowest tempering ratio. A larger tempering ratio resulted in a larger $E r$ and the greater significance of the effect of air velocity on $E r$. For instance, when the tempering ratio was 0.87 , increasing the air velocity from 0.6 to $0.8 \mathrm{~m} \mathrm{~s}^{-1}$ increased $E r$ by only $0.032 \%$, whereas when the tempering ratio was 2.13, the same process increased $E r$ by $6.06 \%$.

According to Dong et al. (2010), the percentage of fissured rice kernels increased as the tempering time decreased. The percentage of fissured kernels may be related to the variations in $E r$; namely, a greater number of fissured kernels indicates a lower $E r$ value. Rupture energy values of faba bean kernel (217.93-1090.6 mJ), soybean (318.34-376.68 mJ), and paddy grain $(13.08-34.39 \mathrm{~mJ}$ in horizontal orientation) were reported by Altuntaş and Y1ldiz (2007), Tavakoli (2009), and Zareiforoush et al. (2012), respectively. In a previous study, it was found that the energy at the rupture point for two corn varieties (White Dent Corn Single Hybrid 10 and Yellow Dent Corn Single Hybrid 155) that were dried naturally at room temperature 
to a moisture content of 30 to $10 \%$ ranged from 64.50 to $85.40 \mathrm{~mJ}$ (AbdEl Maksoud, 2009). The values in our current study ranged from 24.75 to $42.30 \mathrm{~mJ}$.

The Em reflects the ability of a material to resist deformation. Low elastic modulus values under compressive loading demonstrate the ductile behaviour of a material (Pawlak, 2003).

The ANOVA results for changes in the $E m$ of the kernels treated under different drying parameters are presented in Table 5. With the exception of $\mathrm{E}$ (tempering ratio) all five factors exerted significant effects on this index. Based on the $F$ values, the IMC and $\mathrm{RH}$ exerted much greater effects than the drying temperature and air velocity. A quadratic model was the most appropriate model for predicting $E m$, and the results are shown in Table 3.

a

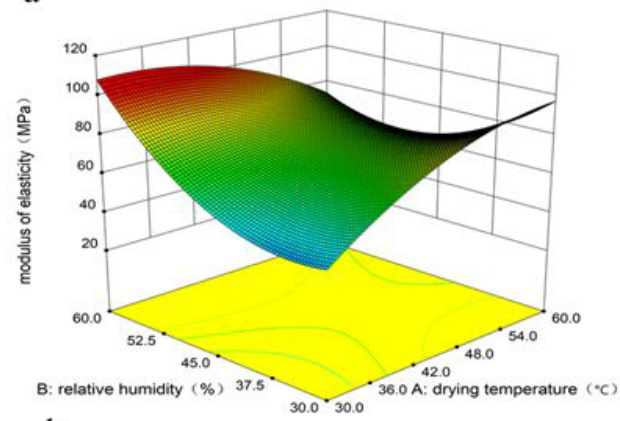

b

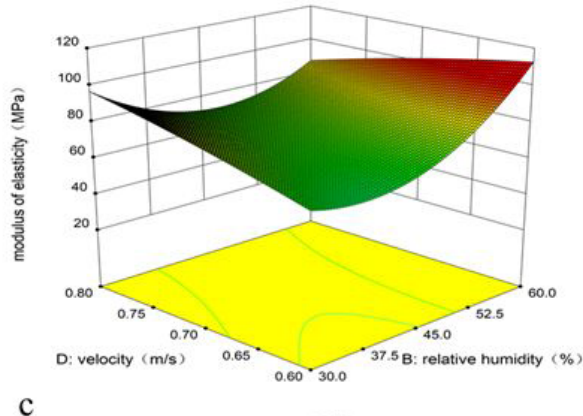

C

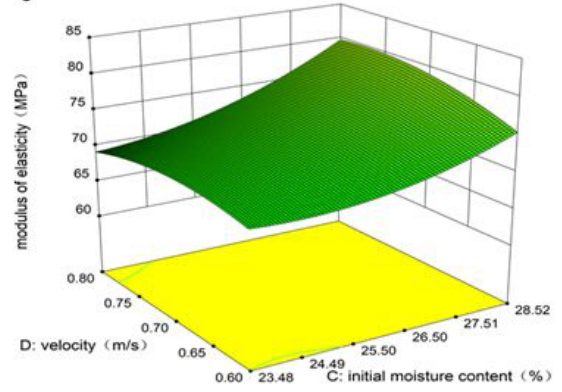

Fig. 3. Simultaneous effect of (a) drying medium temperature-RH (b) RH-velocity and (c) IMC-velocity on modulus of elasticity.

Em varied under different drying parameters (Fig. 3). The simultaneous effects of the drying temperature and RH are presented in Fig. 3a. A larger Em was obtained at a higher RH and lower temperature. Fig. 3b also confirms that a higher RH produces a larger $E m$ at air velocities between 0.6 and $0.65 \mathrm{~m} \mathrm{~s}^{-1}$. As depicted in Fig. $3 \mathrm{c}$, the slope of the graph confirms the results obtained from the $F$ values, showing that the IMC had a much greater effect than air velocity on this index, and greater air velocity resulted in a more significant influence of the IMC on the Em. When the velocity was $0.6 \mathrm{~m} \mathrm{~s}^{-1}$, the $E m$ increased by $7.74 \%$ (69.98-75.39 MPa), while the IMC increased from 23.48 to $28.52 \%$, and when the air velocity increased to $0.8 \mathrm{~m} \mathrm{~s}^{-1}$, the index increased by $15.26 \%(69.22-79.78 \mathrm{MPa})$.

Shelef and Mohsenin (1969) studied the mechanical properties of corn kernels under various loading conditions and with various moisture contents, and the values of $E m$ in their experiments ranged from 82.74 to 1813.32 MPa. The modulus of elasticity of African nutmeg (201.5-41.30 $\mathrm{N} \mathrm{mm}^{-2}$ ), safflower seed (106.13-90.35 MPa), and red bean grain (253.26-93.06 MPa), were reported by Etekpe (2008), Etekpe (2008), Kiani et al. (2011), and Khodabakhshian and Shakeri (2012), respectively. Minaei (2014) showed that the modulus of elasticity of corn kernels ranged from 294.188 to $188.783 \mathrm{MPa}$ after drying at $40-70^{\circ} \mathrm{C}$. In comparison, the elastic modulus values ranged from 37.74 to $101.56 \mathrm{MPa}$ in the present study.

Based on the data shown in Table 6, the effects of the air velocity and tempering ratio on brittleness were not significant, whereas the drying temperature, RH and IMC significantly influenced brittleness. In terms of $F$ values, temperature exerted the greatest effect, followed by the $\mathrm{RH}$ and IMC. The quadratic model presented in Table 3 was the most appropriate model for estimating this index.

a

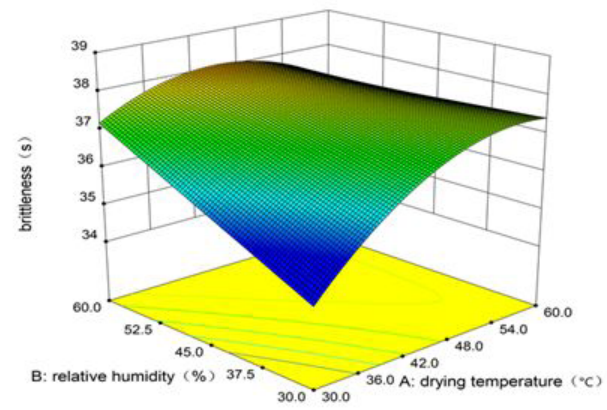

$\mathrm{b}$

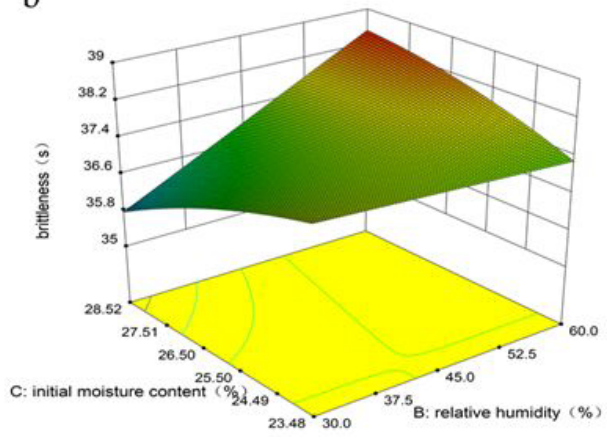

Fig. 4. Simultaneous effect of (a) drying medium temperature-RH and (b) RH-IMC on brittleness.

Since brittleness was measured by calculating the time taken to reach the rupture point, a smaller value indicated more brittle corn. The simultaneous effects of drying tem- 
perature and RH on brittleness are illustrated in Fig. 4a. Generally, brittleness gradually increased as the drying temperature increased. The lowest value of brittleness was obtained at the lowest temperature and lowest RH. Additionally, the effect of temperature on brittleness was more pronounced at a lower $\mathrm{RH}$. As reported by $\mathrm{Li} \mathrm{Li}$-juan (2013) the structural properties (porosity, shrinkage, etc.) of dried products are the main factors affecting the brittleness of the goods. This finding could explain why the higher drying temperature exacerbated brittleness. Higher temperatures caused corn kernel shrinkage and poor porosity, thereby increasing the brittleness value.

Table 6. ANOVA of the influence of various drying parameters on the brittleness of corn kernels

\begin{tabular}{lccccr}
\hline Source & $\begin{array}{c}\text { Sum of } \\
\text { squares }\end{array}$ & DF & $\begin{array}{c}\text { Mean } \\
\text { square }\end{array}$ & $F$ value & Prob. $>F$ \\
\hline Model & 24.83 & 14 & 1.77 & 17.14 & $<0.0001$ \\
$\mathrm{~A}$ & 4.01 & 1 & 4.01 & 38.71 & $<0.0001$ \\
$\mathrm{~B}$ & 2.81 & 1 & 2.81 & 27.16 & $<0.0001$ \\
$\mathrm{C}$ & 1.09 & 1 & 1.09 & 10.53 & 0.0022 \\
$\mathrm{D}$ & 0.21 & 1 & 0.21 & 2.04 & 0.1604 \\
$\mathrm{E}$ & $2.440 \mathrm{E}-003$ & 1 & $2.440 \mathrm{E}-003$ & 0.024 & 0.8787 \\
$\mathrm{AB}$ & 0.59 & 1 & 0.59 & 5.72 & 0.0211 \\
$\mathrm{AE}$ & 1.85 & 1 & 1.85 & 17.87 & 0.0001 \\
$\mathrm{BC}$ & 3.29 & 1 & 3.29 & 31.76 & $<0.0001$ \\
$\mathrm{BD}$ & 0.73 & 1 & 0.73 & 7.06 & 0.0109 \\
$\mathrm{BE}$ & 4.13 & 1 & 4.13 & 39.88 & $<0.0001$ \\
DE & 0.45 & 1 & 0.45 & 4.35 & 0.0429 \\
$\mathrm{~A}^{2}$ & 1.82 & 1 & 1.82 & 17.58 & 0.0001 \\
$\mathrm{C}^{2}$ & 2.01 & 1 & 2.01 & 19.38 & $<0.0001$ \\
$\mathrm{D}^{2}$ & 1.81 & 1 & 1.81 & 17.49 & 0.0001 \\
Residual & 4.55 & 44 & 0.10 & & \\
Lack of fit & 1.43 & 28 & 0.051 & 0.26 & 0.9991 \\
Pure error & 3.13 & 16 & 0.20 & & \\
\hline
\end{tabular}

As shown in Fig. 4b, a lower RH value potentially reduced brittleness, and the lowest brittleness was observed in the samples with the highest initial moisture content. The slope of the graph shows that RH exerted a more significant effect on the brittleness of the samples with a higher IMC. When the IMC was $23.48 \%$, a significant change in brittleness was not observed when RH ranged from 30 to $60 \%$; however, as IMC increased to $28.52 \%$, brittleness changed by $3.09 \%$ within the same range of $\mathrm{RH}$ values.

\section{CONCLUSIONS}

1. In this paper, the mechanical properties of dried corn kernels were accurately measured by controlling the different drying conditions, including the temperature, relative humidity, velocity of the drying medium, tempering ratio and initial moisture content of corn.

2. The quadratic model successfully adapted to the changes in mechanical properties observed after drying under different drying conditions.

3. The drying temperature, relative humidity and initial moisture content generally exerted more significant effects than the air velocity and tempering time on the mechanical properties of the corn kernels. When other drying factors were set to zero, the rupture energy (31.81-37.89 mJ), modulus of elasticity (59.12-66.07 MPa), and brittleness (35.81-37.25 s) increased as the drying temperature increased from 30 to $60{ }^{\circ} \mathrm{C}$. The rupture force $(174.84-201.19 \mathrm{~N})$, rupture energy (29.26-33.28 mJ), modulus of elasticity (84.27-101.74 MPa), and brittleness (36.87-38.09 s) increased as the relative humidity increased from 30 to $60 \%$.

4. Among the indices studied as indicators of the mechanical properties of corn kernels, rupture energy and brittleness were identified as the best ones since they reflect the energy requirements and cracking sensitivity of corn (the time it takes to break) during milling. Based on our results, we recommend a lower drying temperature and lower relative humidity for processing and milling to consume less energy and produce corn kernels that are easier to grind.

\section{AKNOWLEDGEMENTS}

The authors wish to express their gratitude for the funding support received under the project "The key technology and equipment research and development of the paddy temperature-varying intelligent drying system", grant number 2016YFD0401001.

Conflict of interest: The authors declare that they have no conflict of interest.

Compliance with ethical requirements: This study does not contain any experiment involving human or animal subjects.

\section{REFERENCES}

AbdEI Maksoud M.A., 2009. Mechanical properties of corn kernels. J. Agric. Eng. Res., 26(4), 1901-1922.

Altuntaş E., Yıldız M., 2007. Effect of moisture content on some physical and mechanical properties of faba bean (Vicia faba L.) grains. J. Food Eng., 78(1), 174-183. https://doi. org/10.1016/j.jfoodeng.2005.09.013

Aquerreta J., Iguaz A., Arroqui C., Vírseda P., 2007. Effect of high temperature intermittent drying and tempering on rough rice quality. J. Food Eng., 80(2), 611-618. https://doi. org/10.1016/j.jfoodeng.2006.06.012

ASABE, 2012. Moisture measurement d unground grain and seeds. ASABE S352.2 APR1988 (R2012). St Joseph, Michigan.

ASAE, 2003. Compression test of food materials of convex shape. American Society of Agricultural Engineers Standard \#S368.4; ASAE: St. Joseph, MI, 593-603.

Chayjan R.A., Kaveh M., 2014. Physical parameters and kinetic modeling of fix and fluid bed drying of terebinth seeds: terebinth seed drying in fluidized bed. J. Food Proc.Preserv., 38(3), 1307-1320. https://doi.org/10.1111/jfpp.12092

Cheng X.D., Yan X.J., Hu M.Z., 2016. The effect of storage pressure on the mechanical properties of paddy grains. J. Stored Prod. Res., 68, 19-24. https://doi.org/10.1016/j.jspr. 2016.03.003 
Davidson V.J., Noble S.D., Brown R.B., 2000. Effects of drying air temperature and humidity on stress cracks and breakage of maize kernels. J. Agric. Eng. Res., 77(3), 303-308. https://doi.org/10.1006/jaer.2000.0607

Dong R., Lu Z., Liu Z., Koide S., Wei C., 2010. Effect of drying and tempering on rice fissuring analysed by integrating intra-kernel moisture distribution. J. Food Eng., 97(2), 161167. https://doi.org/10.1016/j.jfoodeng.2009.10.005

Doymaz I., Pala M., 2003. The thin-layer drying characteristics of corn. J. Food Eng., 60(2), 125-130. https://doi.org/10. 1016/S0260-8774(03)00025-6

Etekpe W.B.E.A.R.M.D.G.W.W., 2008. Determination of poisson's ratio and elastic modulus of african nutmeg (monodora Myristica). Int. Agrophys., 22.

GB/T, (21017-2007). Technical specification for drying corn in Chinese.

Kalantari D., Eshtavad R., 2013. Influence of different tempering period and vacuum conditions on the rice grain breakage in a thin layer dryer. Cercetari Agronomice in Moldova, 46(4), 5-12. https://doi.org/10.2478/v10298-012-0098-2

Khodabakhshian R., Shakeri M., 2012. Investigation on some mechanical aspects of safflower seed to the design of processing equipment. Int. J. Agric. Tech.

Kiani M.K.D., Maghsoudi H., Minaei S., 2011. Determination of poisson's ratio and young's modulus of red bean grains. J. Food Proc. Eng., 34(5), 1573-1583. https://doi.org/10. $1111 /$ j.1745-4530.2009.00391.x

Lewicki P.P., Jakubczyk E., 2004. Effect of hot air temperature on mechanical properties of dried apples. J. Food Eng., 64(3), 307-314. https://doi.org/10.1016/j.jfoodeng.2003.10.014

Li H., Moray R.V., 1984. Thin-layer drying of yellow dent corn. T. ASAE, 27(2), 581-585. https://doi.org/10.13031/2013.32832

Li Li-juan L.C.-q., 2013. Effect of different drying methods on quality of nelumbo nucifera gaertn products. J. Nuclear Agric. Sci., 27(11), 1697-1703.

Liu X., Jiang. N., Liu, CH.Q., Li D.J., 2011. Effects of drying methods on the quality of black edmame. Food Sci., 32(18), 59-62.

Marques da Silva J.R., Silva L.L., 2006. Relationship between distance to flow accumulation lines and spatial variability of irrigated maize grain yield and moisture content at harvest. Bios. Eng., 94(4), 525-533. https://doi.org/10.1016/j. biosystemseng.2006.04.011
Minaei S., 2014. Effect of drying temperature on mechanical properties of dried corn. Dry. Technol., 32(7), 774-780. https://doi.org/10.1080/07373937.2013.845203

Pawlak G., 2003. Effect of drying on microstructure of plant tissue. Dry. Technol., 21(4), 657-683. https://doi.org/10. 1081/ DRT-120019057

Prasad S., Gupta C.P., 1973. Behavior of paddy grains under quasi-static compressive loading. T. ASAE 16(2), 328-330. https://doi.org/10.13031/2013.37513

Shelef L., Mohsenin N.N., 1969. Effect of moisture content on mechanical properties of shelled corn. Cereal Chem., 46(3), 242-253.

Singh K.P., Mishra H.N., Saha S., 2010. Moisture-dependent properties of barnyard millet grain and kernel. J. Food Eng., 96(4), 598-606. https://doi.org/10.1016/j.jfoodeng.2009.09.007

Talab K.T., Ibrahim M.N., Spotar S., Talib R.A., Muhammad K., 2012. Glass transition temperature, mechanical properties of rice and their relationships with milling quality. Int. J. Food Eng., 8(3). https://doi.org/10.1515/1556-3758.2197

Tavakoli H., Rajabipour A., and Mohtasebi S.S., 2009. Moisturedependent some engineering properties of soybean grains. Agricultural Engineering International: CIGR Journal.

Woźniak W., Niewczas J., Kudra T., 1999. Internal damage vs. mechanical properties of microwave-dried wheat grain. Int. Agrophys., 13(2), 343-347.

Zareiforoush H., Komarizadeh M.H., Alizadeh M.R., 2010. Mechanical properties of paddy grains under quasi-static compressive loading. New York Science Journal, 3(7), 40-46.

Zareiforoush H., Komarizadeh M.H., Alizadeh M.R., Tavakoli H., Masoumi M., 2012. Effects of moisture content, loading rate, and grain orientation on fracture resistance of paddy (Oryza Sativa L.) grain. Int. J. Food Propert., 15(1), 89-98. https://doi.org/10.1080/10942911003754643

Zhang Q., Yang W., Sun Z., 2005. Mechanical properties of sound and fissured rice kernels and their implications for rice breakage. J. Food Eng., 68(1), 65-72. https://doi.org/10. 1016/j.jfoodeng.2004.04.042 